\title{
Green Infrastructure: Connecting People with Landscapes through Urban Retrofitting
}

\author{
Marci Webster-Mannison $^{\mathrm{a}}{ }^{*}$ \\ Malcolm Eadie ${ }^{\mathrm{b}}$ \\ Sally Boer ${ }^{\mathrm{c}}$ \\ Peter Breen ${ }^{\mathrm{d}}$
}

\begin{abstract}
This paper demonstrates a new way to integrate green infrastructure in the urban design of our cities whilst they continue to increase in density. A pilot study demonstrates how the population may be doubled through sensitive infill of the inner-city Brisbane neighbourhoods situated in the historical catchment of Western Creek. Hydrological modelling used MUSIC to size the associated green infrastructure elements and to quantify the benefits in terms of stormwater improvements. The Western Creek Pilot Study reveals the important role that multifunctional green infrastructure has to play in the development of local solutions to urban intensification in response and energy, land, food and water supply pressures as part of a climate change adaptation strategy.
\end{abstract}

\section{Key words: Green Infrastructure; Urban Design; Retrofitting Cities; Climate Change Adaptation}

\section{Introduction}

The Green Infrastructure: Connecting people with landscapes through urban retrofitting research project, funded by the Australian Government's Department of Infrastructure and Transport, is about understanding how to integrate the urban design of cities with green infrastructure to meet the challenges of rapid urbanisation and uncertain future climate scenarios.

The project focus was on developing and evaluating new urban typologies for the Western Creek Pilot Study, located approximately three kilometres South-West of the Brisbane CBD in a 416 hectare catchment of the Brisbane River. This existing inner-city area is considered a highdensity Urban Neighbourhood, however, currently the predominantly character housing area is low density (approximately 10 dwellings per hectare) with about approximately 11,500 residents, or 4,160 households. The planned population increases for the Western Creek neighbourhoods effectively double the existing density over the next twenty-five years. ${ }^{1,2}$

\footnotetext{
${ }^{\text {a }}$ Centre for Sustainable Design, University of Queensland, St Lucia Queensland 4072, Australia.

${ }^{\mathrm{b}}$ E2DESIGNLAB, Sunshine Coast Queensland 4567, Australia.

${ }^{\mathrm{c}}$ E2DESIGNLAB, Brisbane Queensland 4101, Australia.

${ }^{\mathrm{d}}$ E2DESIGNLAB, Melbourne Victoria 3000, Australia.

*Corresponding author: Marci Webster-Mannison m.webstermannison@uq.edu.au http://dx.doi.org/10.14453/isngi2013.proc.48
} 
The Western Creek Pilot Study established the urban densification framework for the hydrological modelling of green infrastructure solutions including the following:

- Viability of introducing green infrastructure related to permeability, land ownership and creation of important ecological links and urban design analysis. ${ }^{3,4}$

- Community Workshop. ${ }^{4}$

- Establishment of the site development potential to increase site density was identified on a site-by-site basis by the researcher, Marci Webster-Mannison and testing of density solutions across over 100 sites considering detailed factors by Masters of Architecture students. 5,4

The green infrastructure solutions were generated through a research-by-design process which integrated the hydrological assessment and modelling of the catchment, development of options, various consultations and design charrettes using the Water ToolKit developed for the Western Creek Pilot Study by E2DESIGNLAB. ${ }^{5,4}$

\section{Modelling}

Quantitative modelling was undertaken by E2Designlab to measure the potential benefits of green infrastructure solutions as part of urban densification of the Western Creek catchment in Brisbane. The modelling uses MUSIC Version 5.01 (Model for Urban Stormwater Improvement Conceptualisation, eWater) and Microsoft Excel to measure change from existing for unmitigated and mitigated (using green infrastructure) urban intensification scenarios.

\section{A. MS Excel water balance model}

A Microsoft excel water balance model was developed for the Western Creek catchment using existing and projected population and land use data for each Scenario and typical water end use data obtained from the literature, to generate annual water balances for potable water demand and use, recycled water demand and use, wastewater (grey and black) generation and reuse, and stormwater and rainwater (from roofs) generation and re-use.

\section{B. MUSIC}

MUSIC Version 5 was used to model the quantity and quality of stormwater flows for the Western Creek Catchment. The model generates estimates of annual stormwater pollutant loads $(\mathrm{kg} / \mathrm{yr})$ and daily peak stormwater flows from which a partial series analysis was undertaken to generate estimates of peak flow for various Average Recurrence Intervals (ARIs).

\section{Existing Scenario: Methods and Results}

\section{A. Stormwater pollutant load and flows}

A MUSIC model, Scenario One_ Existing Situation, was developed to represent the existing conditions in 7 sub-catchments of the Western Creek catchment (Figure 1). Existing land uses were consolidated into the following categories of Detached Residential, Multi-Residential, Commercial, Industrial and Open Space / Forested for ease of modelling using the MUSIC Modelling Guideline parameters. The outputs from MUSIC were then analysed to calculate peak flows using partial series analysis. 


\section{B. Water balance}

The existing water balance for the Western Creek catchment was determined using the total areas (ha) for commercial, low density residential and multi-density residential land uses, dwelling density (dwellings/ha) and dwelling occupancy rates and typical water demands per/person. The results of the water balance analyses show that currently the largest water demands are generated in the low density detached residential land uses which is the dominant land use across the catchment.

Although all water demands in the catchment are currently serviced by the regional potable water supply, the results clearly show that a large portion of that demand could be serviced by alternative water sources such as roofwater, treated stormwater and treated wastewater on a 'fit for purpose' basis.

The significantly high proportion of recycled water demand in the commercial land use is due to toilet flushing being the predominant water demand in these buildings, which can be met using recycled water. The detached low density residential land use has a high proportion of recycled water demand when compared to the multi-density residential areas. Even though recycled water can be used to meet the toilet flushing and laundry demands across both of these residential land uses, the irrigation demand is higher for the detached low density areas due to the large landscaped areas on these larger lots.

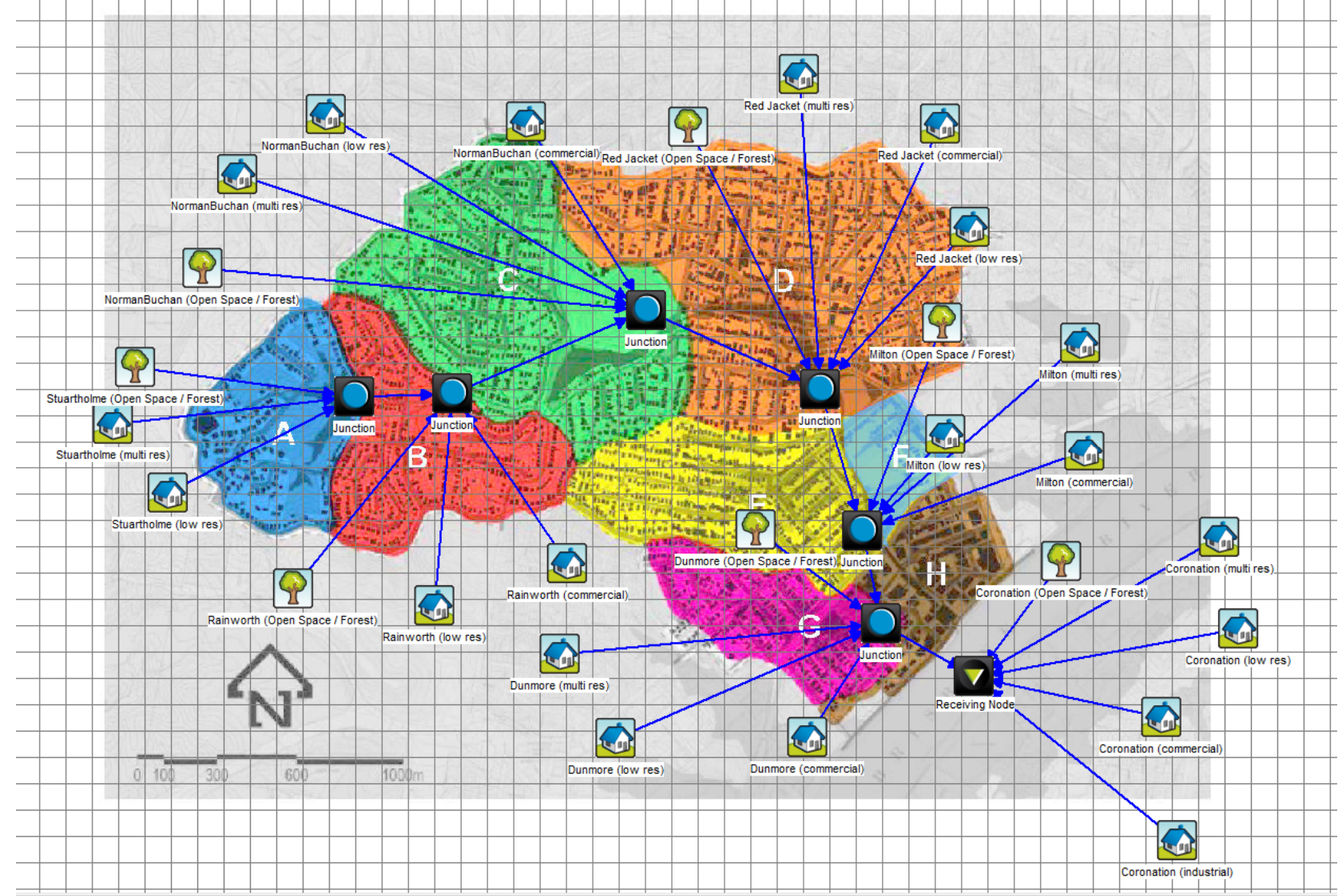

Figure 1. MUSIC model of Scenario One_Existing Situation 


\section{IV. 'Un-Mitigated' Urban Intensification: Methods and Results}

A MUSIC model, Scenario Two_Future Un-mitigated Urban Intensification, was developed to represent the future conditions of each sub-catchment assuming population densification without green infrastructure (Figure 2).

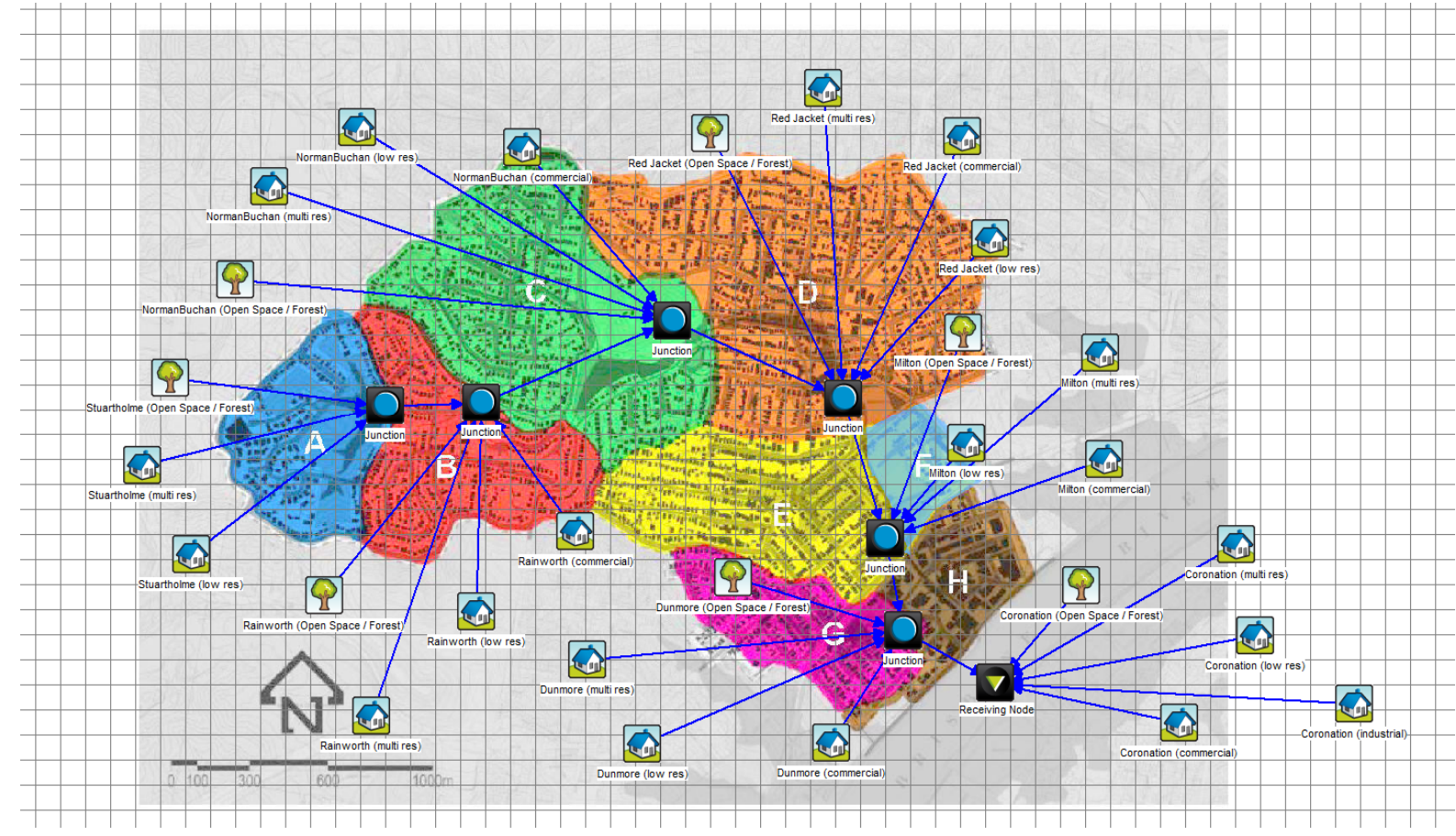

Figure 2. MUSIC model of the future - unmitigated Western Creek Catchment

\section{A. Stormwater pollutant load and flows}

The majority of land use change planned for the Western Creek catchment is conversion of low density residential to medium density residential. The results show that there is a very minor impact on stormwater quality and hydrology (flow) between Scenario One_Existing Situation and Scenario Two_Future Un-mitigated Urban Intensification Scenario due to the relatively minor change (increase) to the overall catchment imperviousness. The results indicate that there would be only a minor impact on local flooding and waterway health from the planned urban intensification. What the results mask however, is that catchment urbanisation to-date has already impacted significantly on flooding and waterway health in the catchment with resultant poor amenity, resilience and ecosystem services.

\section{B. Water balance}

The results of the water balance analyses for existing and future show that there will be a decline in water demands and wastewater generation for commercial and low-density residential areas which can be explained by the reduction in these two land uses in the future scenario. The results show however, a significant increase in total water demand (currently met using 100\% potable water) and wastewater generation associated with the increase in multi-density residential areas. The increase in water demand is largely driven by an increase in demands for uses which require potable water (e.g. bathroom and kitchens) associated with the increase in 
residents, thereby limiting any potential increase in the proportion of total water demand which could be met with the use of recycled water. Compounding this issue is the reduction in irrigation demand due to the conversion of large landscaped detached house lots to medium density residential developments with limited irrigation demand, and the conversion of landscaped areas to hardstand roofs and paving, also resulting in an increase in roof runoff and stormwater runoff.

\section{V. 'Mitigated' Urban Intensification: Methods and Results}

Scenario Two_Future Un-mitigated Urban Intensification MUSIC model was modified to represent same level of population densification with the addition of Green Infrastructure to create Scenario Three_ Mitigated Urban Intensification (Figure 3).

Green Infrastructure measures included the following:

- Provision of rainwater tanks for all new multi-density residential developments connected to internal uses (toilets and laundry cold tap) and for external uses (landscape irrigation) to reduce potable water use.

- Provision of 'extra-over' capacity in rainwater tanks installed in all new multi-density residential developments to minimise downstream flash flood risks.

- Pipe drainage disconnection for roads and other surfaces (roofs and ground level areas) from downstream waterways using on-site and streetscape bioretention to treat residential and commercial areas to protect downstream waterway corridors.

- Provision of an alternative water source (recycled wastewater) for the commercial area in the downstream section of the catchment to reduce potable water use and minimise wastewater production.

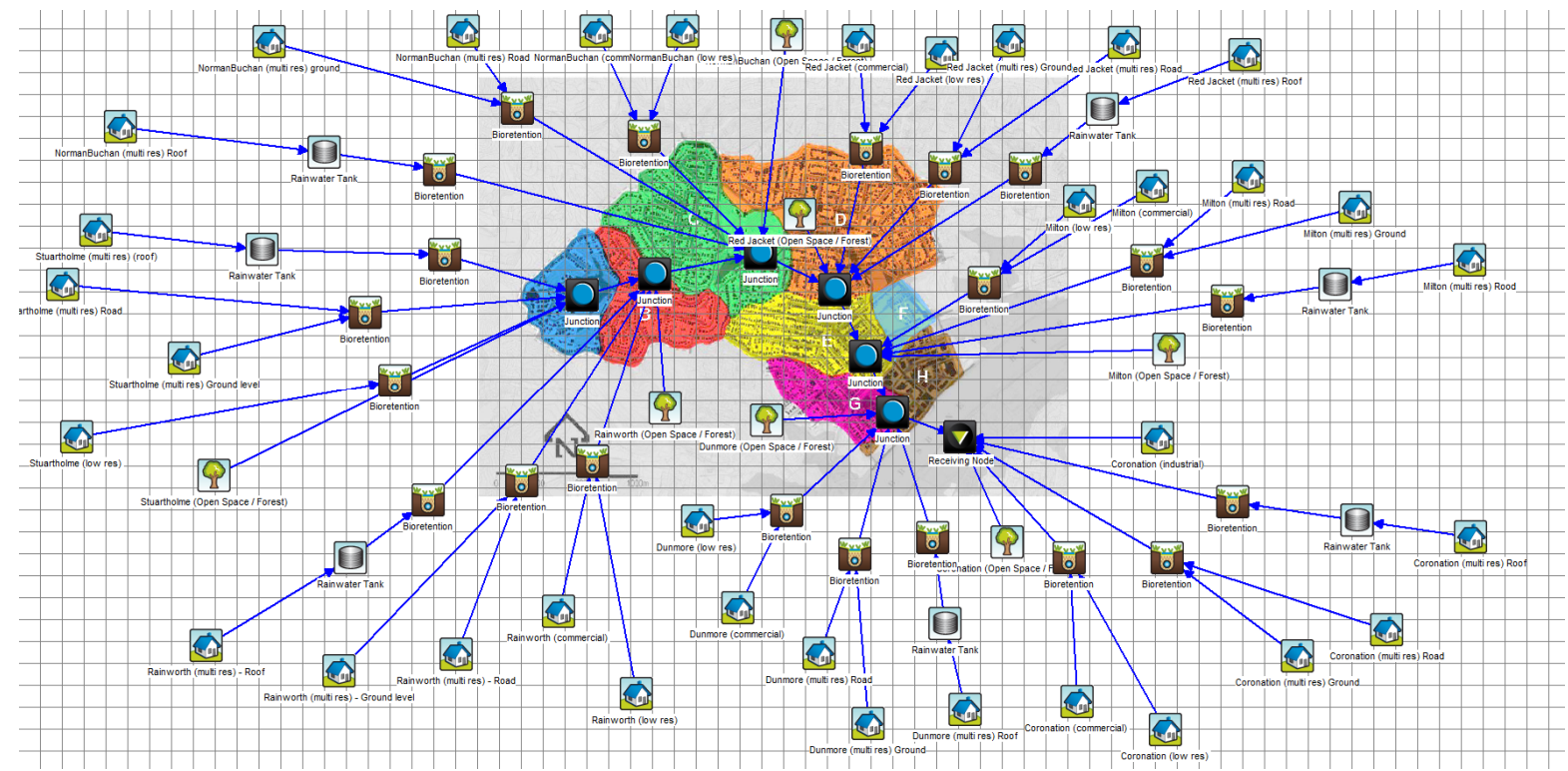

Figure 3. MUSIC model of the future Western Creek Catchment with Green Infrastructure 


\section{A. Stormwater pollutant load and flows}

The partial series analysis results show that green infrastructure can have a significant improvement on stormwater quality and peak flows compared to the existing catchment condition (Figure 4). This highlights that incorporating simple, well understood and tested green infrastructure solutions as part of urban renewal/re-development can allow for urban intensification whilst significantly improving the functionality and amenity of the catchment. Benefits include:

- Reducing hydraulic and water quality pressures on existing waterways assets in the catchment and downstream of the catchment thereby improving their resilience to future extremes and shocks and allowing for higher levels of ecological recovery (remediation).

- Reducing the hydraulic loading on existing aging stormwater drainage infrastructure thereby extending its useful service life.

- Reducing the frequency of nuisance type flooding and associated disruptions to the functionality of the catchment.

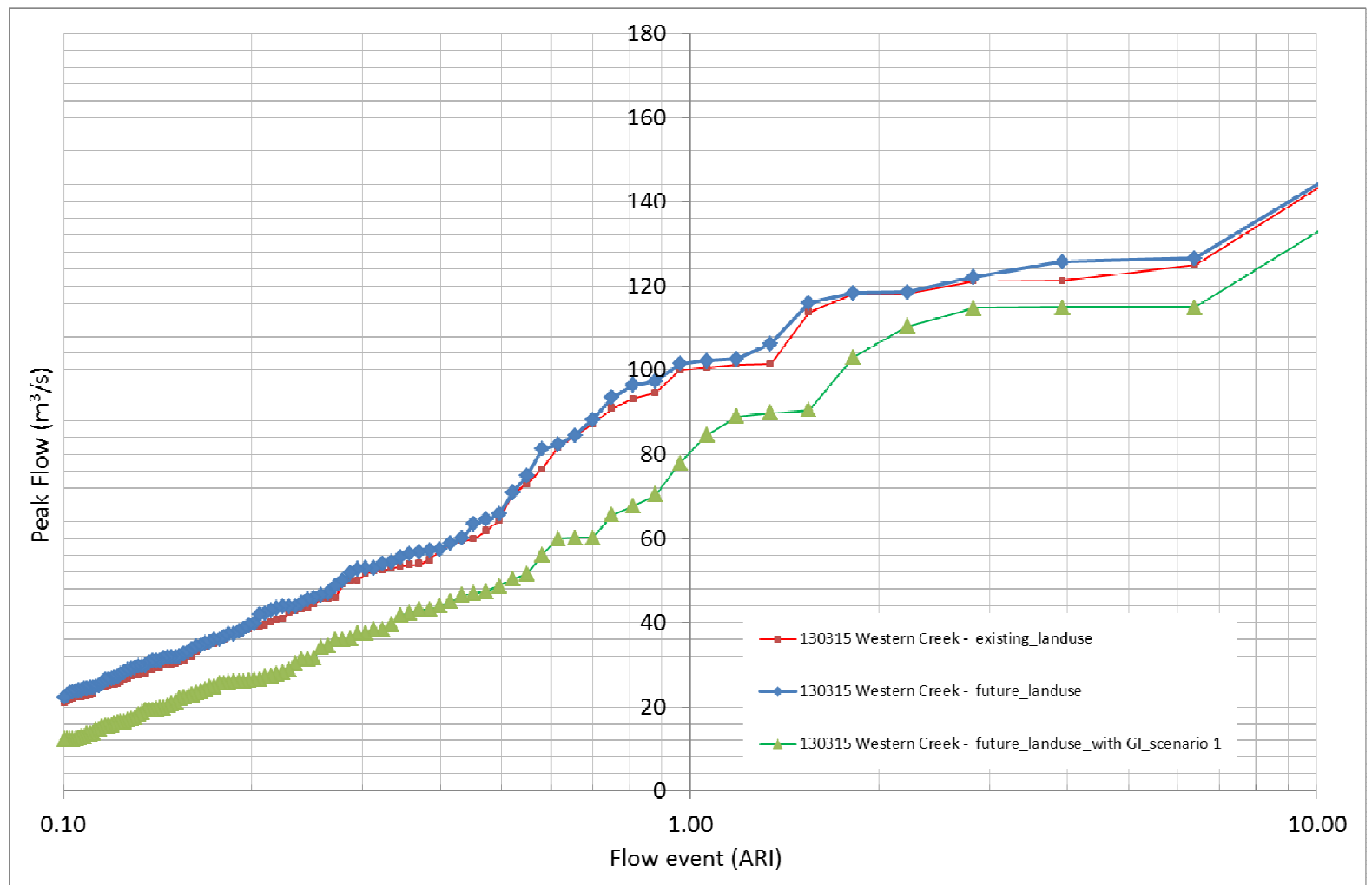

Figure 4. Partial series analysis outputs showing reduction in peak flows associated with inclusion of green infrastructure

\section{B. Water balance}

The Future Water Balance Model was modified to reflect the use of rainwater tanks to meet recycled water demands for new multi-density residential areas and on-site blackwater treatment and re-use to meet recycled water demands for commercial areas. The average annual 'yield' (ML/yr) from installation of rainwater tanks in medium density residential areas was measured 
using the MUSIC model (100\% of the recycled water demand for commercial land uses was assumed to be serviced from on-site blackwater treatment and re-use). The results show that the use of rainwater tanks for all medium density residential developments and the treatment and reuse of blackwater in the commercial land use areas can reduce the volume of potable water used by the catchment to less than existing. Therefore, the use of green infrastructure can be used to successfully achieve population densification in catchments while reducing the overall demand on regional potable water supplies and infrastructure. Furthermore, the reduced discharge of roofwater and blackwater from the catchment (compared to the existing situation), reduces downstream ecological and infrastructure impacts and costs.

The combination of rainwater tanks on medium density residences and blackwater recycling in commercial areas is able to meet only $60 \%$ of the total recycled water demands across the catchment. Therefore, further reductions in the catchment's demand of the regional potable water supply could be achieved by exploring the feasibility of additional recycled water sources, for example, stormwater harvesting and sewer mining. The feasibility of these recycled water sources are highly site specific and although beyond the scope of the current project, further highlight the need for an integrated site-specific approach at the building, lot, street, subcatchment and catchment scale.

\section{Conclusion}

This modelling has highlighted the multi-functional nature of the benefits that green infrastructure can provide when implemented as part of an urban retrofitting and densification. In older urban catchments where natural and built assets are already under-pressure, green infrastructure solutions enable population increases whilst reducing the pressure on existing infrastructure assets. The benefits are multi-functional and resilient with improved amenity and lower overall costs associated with population growth due to avoided and/or delayed trunk water services infrastructure augmentation.

Notable results from the modelling are:

- The inclusion of rainwater tanks in new multi-density residential developments with a provision for extra-over capacity for flood attenuation can reduce (compared to existing) peak stormwater flows at the catchment outlet by up to $30 \%$ for more frequent events;

- Implementing on-site and streetscape bioretention to treat stormwater runoff from new multi-density residential and new commercial areas can provide significant water quality benefits for downstream waterways (between $40 \%$ and $70 \%$ reductions in annual pollutant loads compared to existing);

- Provision of alternative water sources (i.e. recycled wastewater for the new commercial areas and rainwater for new multi-density residential) can reduce the catchment's demand on regional potable water supply by $30 \%$ compared to existing.

\section{References}

${ }^{1}$ Brisbane City Council, The Brisbane CityShape 2026, URL: http://www.brisbane.qld.gov.au/planning-building/current-planning-projects/neighbourhood- 
planning/neighbourhood-planning-and-urban-renewal/listening-to-the-community/brisbanecityshape-2026/index.htm (Accessed 3 Aug 2013), 2006.

${ }^{2}$ Department of Infrastructure and Planning, Draft South East Queensland Regional Plan 20092031, Brisbane: State Government of Queensland, 2008.

${ }^{3}$ Grgic, V., Surfacing Urban Creeks as Green Infrastructure Corridors: Integrating conservation efforts, sustainable water management and smart land-use planning for South East Queensland Case study of the Western Creek catchment, Dissertation for Master of Architecture, Brisbane, University of Queensland, 2009.

${ }^{4}$ Webster-Mannison, M., Eadie, M., and Boer, S., "Urban Water ToolKit: raising creeks and growing cities," 6th International Urban Design Conference, Sydney, 2013, pp. 33-38.

${ }^{5}$ Webster-Mannison, M, "Growing cities from within: urban agriculture in inner Brisbane," $6^{\text {th }}$ Making Cities Liveable Conference, AST Management, Nerang, QLD, 2013, pp. 216-230. 